\title{
LABOR AGEISM AS A FORM OF SOCIAL BEHAVIOR AND ITS CONSEQUENCE
}

\section{Savelyeva Olesya Vyacheslavovna}

Aspirant

Rostov State University of Economics

Marketing Specialist

City Clinical Hospital named S.P. Botkin

Supervisor: John Violaris

Professor

\begin{abstract}
The relevance of the theoretical understanding of various forms of social behavior in modern society is due to increasing tendencies to consider problematic issues of life in relation to a person, his personality and the basics of his social behavior. The term "social behavior" is considered through the definition of this concept in various social and psychological approaches, in order to highlight the characteristics of labor ageism as a negative consequence of the formation of distorted attitudes in modern society.

The most significant aspects are considered from the perspective of assessing the being of a modern person, his status role, and conditions of activity in social interaction as a whole. Understanding social behavior and its consequences allows us to substantiate the main tasks and means of social management to solve these problems in almost all areas of society.

This article examines labor ageism as a form of social behavior within the framework of the problem of the development of professional activity of people over 45 years old, comprehends the main approaches to this problem, and defines ways to solve it.
\end{abstract}

Key words: ageism, education, social behavior, age discrimination.

A review of scientific theories indicates an insufficient elaboration of the term "social behavior", which makes it possible to single out its interdisciplinary essence and to determine some basic principles for determining the definition in the concept of "social action". Psychological theories distinguish under the influence of "a concrete act localized in space and time in the activity of a public subject in transforming a social situation according to his needs and goals and realized by changing the behavior, attitudes, and aspirations of other individuals or communities. 
In social sciences, the understanding of M. Weber prevails, which means the simplest unit of social reality, which denotes the conscious action of a person, focused on the behavior of other people, as well as society as a whole in different periods (Weber, 2006).

Empathy and resistance to conflict. Older employees are usually good at putting themselves in the shoes of a client, colleague, partner and a strong negotiating position. They often play the role of emotional leaders in a company. At a critical moment, this is important - they will listen, calm down, and set a positive background.

Respect for standards and discipline. Although people over 45 can do the job without instructions, if there is an instruction or regulation, they usually treat its rules with respect. In addition, they demand the same from young colleagues.

Loyalty to the company. They perfectly charge this feeling with younger ones.

Over time, the advent of new research age-related stereotypes have not become less common. Older workers are still considered less productive, less adaptable, and tougher and rely only on retirement. The facts are the opposite. Aging does not affect productivity, with the exception of activities with high physical activity. In fact, intellectual abilities can improve with age, especially if the employee remains active and involved. Teachers, professors, doctors, writers, lawyers and judges, among other things, remain productive and highly motivated with age and adapt to new technologies. Despite the corporate trend toward early retirement, an increasing number of older workers want to continue to work after reaching sixty-five years, which are considered the "normal" retirement age (Raymond, 2001).

Employers usually make decisions affecting older workers who believe that these workers are no longer able to work adequately. Thus, older workers are exposed to unfavorable decisions when hiring, motivated by false and stereotypical representations of age, regardless of the actual state of their physical or mental abilities. Older workers face two types of employment problems. An older worker may have difficulty fulfilling work duties due to actual impairment of physical or mental abilities. Another may work for the employer, who assumes that the physical or mental abilities of the employee have decreased, even if in fact it is not. Employers readily assume that deterioration occurs simultaneously with age, given the fact that using this stereotype is much simpler and cheaper than testing the general abilities and qualifications of each of their senior employees.

Age closes the door. This severely limits the range of employment options available to an older employee. An older employee can culminate in his career and 
feel that he has more opportunities to offer his employer than ever before, and yet discover that age is a serious barrier to further career advancement. The position that the employee can aspire to is most likely to be awarded to a much younger person who lacks experience and possibly the enthusiasm and dedication of a senior employee. The younger employee has only his youth to recommend it, but this will be more than enough for the employer. Youth will be rewarded with promotion, while older workers will remain in their current position. A year later, an older employee may be reduced or forced to resign under any pretext. The chances of finding another position are practically nil.

The result is a paradoxical situation. It is difficult for a young man without work experience to find this job, because no one wants to engage in training a young employee. An experienced employee who is approaching retirement age is denied only because he will soon retire (even if he is not going to retire). Despite public condemnation of such forms of expression of social behavior, in practice, such discrimination is still present, as recent studies show (Bratt et al., 2018).

Elderly and low-skilled workers may be reluctant to participate in continuing education activities, enroll in courses due to a lack of understanding of economic benefits, fear of returning to class and passing exams, and lack of programs tailored to meet their special needs.. Fear of returning to class may be the result of low confidence in one's ability to form and develop new skills. Convincing employees older than 45 that they are capable of successful training and providing them with support can reduce their lack of self-confidence. Examples include successful student education courses that help older students prepare for college conditions, such as memory improvement and learning programs. Flexible class planning, peer mentoring, unobtrusive counseling, tutoring, help navigating the system, and allowing students to interact with other students are additional mechanisms that contribute to student success. It is also important that counselors and teachers understand the special needs of students of this age. Reducing the fear of passing exams can be achieved by improving learning skills, learning how to better prepare for the exam and how to relax in front of it.

Employers in the United States and other countries may be reluctant to provide training opportunities for older workers due to the alleged lack of return on investment due to the time required to recover training costs. In fact, a 50-year-old worker is likely to stay with the employer longer than a 20 or 30 -year-old. Due to the increase in the retirement age, a 50-year-old worker can still work at the age of 70 . Gaining a deeper understanding of how adults benefit from lifelong learning is 
important in both theory and practice, as adult education is the key to solving many social problems (Sargeant, 2011).

However, as pedagogical research shows, in order to share your experience, you need to "be able to teach." Not always, an experienced engineer can methodologically transform his practical experience into a theoretical concept, and not always, he can possess the necessary competencies for training. Moreover, what in this case turns out? We have an employee over 45 who has decent experience in the practice of his work, who can and wants to transfer it, but does not know how. In most cases, such employees finish their retirement and leave, but their value and significance lies precisely in their ability to educate and transfer their knowledge, skills and abilities. In this case, such an employee can learn pedagogical technologies, fill in the gaps in theoretical knowledge, learn a related profession, etc. However, this is where the main problems lie. A person older than 45 years is not characterized in our social society as a student. If he wants to get an education, he can go to university or college and pay for it - this is only welcome. In addition, if he wants to be a student again? Only consciously, with a certain motivation, with the desire to actualize your experience in new knowledge and, possibly, a new profession? To do this, he just needs the support of the state and universities in the possibility of receiving a scholarship or grant for training.

As our analysis has shown, educational institutions practically do not offer free places to study for people over 45 under "student programs", although there is no legislative reason to refuse such people to get an education, but in fact, in this age period, many have obligations to maintain families, children that explains the impossibility of obtaining a full-time budget. This indicates negative trends in leveling the constitutional principles of equality in the social behavior of the state itself. The paradox of such positions It means that without training, people over 45 cannot compete with their young colleagues studying in new conditions using modern techniques and the latest technologies, while young people who have received a good education have basically only a theoretical basis, a minimum of experience work, which weakens her position in front of the employer (Osborne, 2003, Osborne et al. 2004). At the same time, it is no secret that employers consider the lack of knowledge of modern technologies, less flexibility and openness to new knowledge, new experience a disadvantage of older employees. Nevertheless, this problem is solved. It often turns out that an employee over 45 years old, being an excellent expert in a certain field, is unaware of the technical capabilities that increase the effectiveness of work in his field. Another drawback that employers often attribute to older workers is 
their less ability to learn. Which, again, means less susceptibility to new methods and technologies of work, new experience (Lynch).

The social behavior of society is fueled by traditional ideas that people over 45 have already received basic education, they have work experience, and if they cannot be productive at their age, this is due precisely to their age and personality characteristics, and by no means the demands of society. In our opinion, these clichés are hypocritical, since this problem has a fairly wide public resonance in both Russian and foreign media.

The analysis of scientific research proves the inconsistency and illegitimacy of such allegations. For example, researchers establish a lack of correlation between the productivity of employees of the same position and their age (Backes-Gellner et al., 2011). At the same time, the social behavior of older colleagues is distinguished by greater discipline, lack of safety practices, loyalty to the enterprise and the stability of professional activities (Boersch-Supan \& Weiss, 2007). Scientists also refute the view that the older the person, the less pronounced cognitive learning abilities. Motivation and a conscious need for learning is the best way to self-organize the educational process, and life and professional experience allows us to draw an analogy of a new education with already acquired practical experience, which together increases the effectiveness of educational activities of people over 45 years old. The main characteristics of persons over 45 years of age with regard to education can be attributed to the following:

- A high level of motivation, in most cases, people of age are diligent students, since the decision to continue training is made consciously, and not spontaneously. As a rule, this is a serious choice and a person realizes the need time and financial costs, he is ready for this situation. Therefore, having made this choice, adult students are motivated to achieve high results.

- Focus on education. Higher education by adult students, as a rule, is aimed at solving certain problems and achieving a number of goals due to a specific life situation. In this context, the practical approach of adult students to education is clearly observed, the desire to acquire knowledge and skills that can be directly and soon applied to professional or any other activity. - Experience. Adult students have life and professional experience, as well as knowledge acquired at the previous stage of training. Adults, as a rule, actively participate in the educational process, using their own experience and knowledge; they can make a significant contribution to their education and to the education of other students. 
- Predisposition and readiness for independent and critical thinking. Adult students are more independent, have an established worldview and prefer independent forms of educational activity.

- A wide range of responsibilities and lack of time. As a rule, an adult has a job and a family, as well as certain social responsibilities, which undoubtedly affect the learning process (Knowles et al., 2005).

The main goal of each type of education is to create and maintain the ability of citizens to be active. This also applies to adult education, the purpose and functions of which cannot be separated from other functions of the education system. Adult education allows you to adjust and complete the social role of public education, vocational training and higher education: social openness, creation of equal opportunities and mobilization nature. Based on this concept, adult education provided and still provides additional tasks of higher education. At the end of the last century, the traditional compensatory function of adult education faced new challenges. Because of the social, political, economic, scientific and technological progress of the twentieth century, the rate of change in society and the economy has increased significantly. Accordingly, revolutionary changes also took place in the human resources market: in almost all areas of social and economic life, systematic retraining was necessary, even if the conditions of employment remained unchanged. Thus, the concept of further education has acquired a new meaning: it means less and less adding, completing, correcting one's knowledge; this more and more refers to the transition to something new. In modern society, a new function of adult education is learning how to overcome various complex socio-political and economic crises that are the result of modernization. Education has become a lifelong challenge (Óhidy, 2008).

In the past two decades, the field of adult education has received increased attention throughout the world, especially in countries where the older adult population has reached an undeniably high proportion. This is not surprising when you consider that population aging is perhaps the most important trend of the 21st century. All over the world, two people celebrate their sixtieth birthday every second - almost 58 million sixty years a year. According to forecasts, by 2050 the picture will change significantly: one in five people in the world will be over 60 years old, the aging of the population can no longer be ignored. Population aging occurs in countries around the world, both more and less developed. Life expectancy has increased, and fertility rates have decreased, which has led to an increase in the share of the world's population in older age groups and a smaller share in traditional 
working-age groups (Findsen \& Formosa, 2016). There are more working people of retirement age. All this suggests that in the next decade, companies will face an increase in the number of employees over 45 years of age whose discrimination can result in a shortage of labor. All this suggests the need to develop ways to improve social behavior in this area, to present some model of adaptation of people over 45 to new working conditions, with the support of educational and state organizations, in order to optimize social attitudes to the problem of age discrimination under consideration. Because of the economic crisis that Spain is still experiencing, $5,891,998$ people registered with the unemployment office, according to statistics from the National Public Employment Service (SEPE, 2015) for January. Particularly significant are unemployment rates in some specific categories of the population, which includes many people over 45 years. The unstable economic situation creates categories of the population that are especially vulnerable and hushed up by society. Aware of the vulnerability of these people and groups, the public administration considers them to be "high priority categories of the population" (Amber \& Domingo, 2016), which means that, among other issues, they have priority in participating in training events to guarantee their access to the labor market. Faced with this panorama, the Eurydice (2015) European Commission report recommends flexible training so that it can be coordinated with family responsibilities and an active job search. However, at present, the problem is hiding due to measures and subsidies that are clearly insufficient and do not resolve the situation. The proposed training does not meet the needs of the population and does not solve pressing economic difficulties, since it does not significantly improve their opportunities for real employment (De la Rosa, 2014).

A recent study (Amber \& Domingo, 2016) shows that unemployed people over 45 in Spain are a particularly vulnerable population. The support, employment and training measures designed for them are insufficient, which created a problematic social situation that was hidden by traditional media. However, existing internet blogs offer new ways of expressing problematic issues with alternative discourses that show the severity of this reality. Researchers have selected and analyzed Spanish training and employment blogs that address this topic. The sample corresponds to a set of blogs that, according to the group of experts, were rated as the most significant and relevant, the Delphi technique was used for the sample, and all the material was studied using discursive analysis.

Focusing on a group of unemployed people between the ages of 45 and 64, the authors identified $33.1 \%$ of Spanish unemployed, according to data from the fourth 
quarter of 2014, obtained from a survey of the active population (EPA) of the National Institute of Statistics (INE). 2014). However, it was revealed that this sample is also having trouble from a number of other circumstances. Unemployed people over the age of 45 are more openly affected by social rejection: companies ignore them, the media do not consider them above the level of simple rhetoric, and social benefits quickly end, making them feel more and more forgotten by society. They fell into this situation of unemployment and dependence on the minimum subsidy. Unemployment, especially over extended periods, has serious consequences that go beyond economic instability (Del Pozo et al., 2002), with devastating effects on its victims. These people lose their independence, and at the same time - a sense of dignity, expectation and hope. This leads to a "personality crisis" and a "feeling that he is not good enough" (Dubar, 2002), with serious consequences, not only psychological (anxiety, panic attacks, etc...), but also physical (fatigue, pain etc.). To cope with this dramatic reality and the unstable economic, working and social situation, these people find support on the Internet. Social networks act as a way to escape, which allows them to express their thoughts, communicate with each other, share their experiences and learn the opinions and advice of experts on employment issues that offer their knowledge to society. Thus, thanks to the interactive communication capabilities offered by the Internet (Chou et al., 2010), social networks are a viable space for social and cultural exchange (Nef et al., 2013). In this sense, blogs are becoming more and more important in this space, as they allow you to generate and disseminate a lot of reasoning that are not found in other types of texts. At the same time, as practice shows, this does not solve the problem of unemployed citizens over 45 years old, all of them, by their own admission, need training that is flexible enough, and possibly remote, so as not to break away from everyday life and family. Moreover, for this it is necessary to create a special policy of grants for education for people over 45 years old, coordinated with the social policy of the state.

For a complete picture, it is necessary to consider the features of various countries considering the possibility of educating people over 45 years old.

There are no undergraduate fees at German state universities, and this applies to both German students and foreigners, regardless of their nationality. In particular, Germany hosts many online universities with no tuition fees. This usually applies to international students around the world, inside or outside the EU / EEA zone. The only fees required are called "administrative fees", which cost around 100-200 euros 
per year, and they are intended for student services, covering the cost of bus tickets to the university, student canteens and much more.

Every year, the German Academic Exchange Service (DAAD: Deutscher Akademischer Austausch Dienst) provides financial support to more than 120,000 highly qualified German and foreign students who live and study in Germany for free or at a more affordable price. Scholarships for study in Germany are offered to domestic and foreign students of all levels, as well as scientists and researchers. Note that for scholars over 45 years of age such scholarships are not always suitable, since not all older people with work experience who want to share it, but who do not have this education for even training in their work profile, can receive a scholarship.

In the UK, there are opportunities for adult education, but a number of problems accompanies them. The curriculum for adult education, as a rule, focuses on leisure and hobbies, although at present most of them are professionally oriented and accredited, compared with previous periods. Perhaps the leisure nature of adult education is one of the reasons why it continues to be considered marginal activity with low status. Colleges of additional education conduct large professional programs for adults, both at work and outside it. Only recently has the idea of lifelong learning become widespread, adult education recognized as an important area. An important milestone is the creation of the Open University. However, the country does not have large-scale scholarship programs for adults. In Norway, there are no scholarship funds for older students, although there is no paid education at state universities and colleges, older people do not have the opportunity to receive a grant for education, since the entire bachelor's education system is built on young people. In Austria and Hungary, the situation is similar.

The exception is Sweden, where measures are being taken to increase formal and non-formal adult education. This bar is set at the age of 25 and above. Changes in the field of education are associated with such phenomena as the aging of the European population. On the Swedish labor market, this is now quite tangible. Therefore, in the country $20 \%$ of the population are people over 65 years old, and the average life expectancy is very high - 79.9 years for men, 83.7 years for women. To solve the problem, it was decided to increase investment in education. Since 2018, for public and private general and special courses alone, investments have amounted to SEK 641 million annually (5,000 places). Investments in universities and colleges amount to SEK 353 million. For citizens over 25 years old, the government provides an opportunity to receive education and improve their qualifications throughout their lives throughout Sweden. Education is partially funded by the state. Sweden's adult 
education policy is driven by the requirements of the modern economy, as well as the rapid development of technology, which necessitates regular training for employees. This form of training has a low threshold for admission, the ability to learn on the job is important.

Nevertheless, we can note that in Europe a somewhat one-sided attitude towards "non-traditional" students or students older than 45 years prevails. In fact, every citizen has the right to study at any age, but the restriction placed by the university on the requirements for study does not actually allow a person to study without the support of a grant or scholarship. There are no specially allocated programs for training people over 45 years of age, which indicates a low level of social responsibility to the category of people who are in the age group of 45 years and older who want to change their professional orientation, share their own experience, train young specialists, and for this they appropriate education is needed.

Age restrictions on higher education are regulated not by one European law, but by the laws of each European country individually. For this reason, talking about whether there are age limits in Europe for education is not true. In European countries, there is absolutely no age limit for admission to the university (only creative specialties can make exceptions). Europeans receive education in retirement age. The average student age in Germany is 27 years old. However, for example, it can definitely be argued that there are no age restrictions on obtaining higher education in the Czech Republic, at the same time, student age is limited to 26 years. This means that only up to this age a person studying in an educational institution in the Czech Republic can receive discounts on the international ISIC student card, which is used by students all over the world.

Accessibility of education is also facilitated by measures to support and develop academic mobility, that is, to remove obstacles to the receipt of all types of educational services by students of any age in any country of the European Union. Thus, the policy and steps taken by the European Union regarding a higher vocational school demonstrate its intentions in every way to stimulate high-quality adult education.

Age-related discrimination is observed in the context of educational grants from a number of Asian countries, where scholarships for foreign students are currently widespread. So, in the process of research, several government programs were discovered. The Government of the Republic of Korea has established scholarships for international students who wish to receive a bachelor's, master's, or $\mathrm{Ph} . \mathrm{D}$. degree in Korea. At the same time, the requirements indicate that students who 
enter the bachelor's program should be no older than 25 years old, and students who enter the magistracy or graduate school should not be older than 40 years old. Similar programs exist in the People's Republic of China. Requirements for applicants are also similar. Applicants for scholarships for undergraduate studies must be under the age of 25 years, to obtain a master's degree - 35 years old, doctors $(\mathrm{PhD})$ - 40 years old. The Japanese government scholarship also includes age restrictions. For postgraduate or graduate studies, a candidate must be under 35 years old. Higher education for citizens of these countries over 45 is also difficult.

In a number of countries, the problem is not the acquisition of higher education by a population older than 45 years or the improvement of their qualifications, but the acquisition by them пожилых людей. Therefore, in Argentina, in order to solve a number of socio-economic problems in the 1980s, the formation of educational opportunities for middle-aged and older people began. The creation of a middle and third-age department at the Entre Rios National University in 1984 is considered a significant milestone in adult education in Argentina. Another informal educational scheme for older people, launched in 1993, is Open Universities for the Third Age. There are currently seven institutions. An open approach to the curriculum is a good choice for this group of people, as they can choose courses in accordance with their interests. The state supports the compulsory education program for the population, subsidizes the training of people over 60 who have not received basic education. Recently, the educational private market has also met the cultural needs of middle and upper class seniors by offering courses.

Education is considered a fundamental right and as such is included in some government policies for adults and seniors in Brazil. However, there is no law aimed solely at educating people of the third and fourth age. Brazilian education legislation includes basic education (elementary school, high school and high school) and higher education. Continuing education in the context of aging in Brazil is currently in the fields of formal and non-formal education. By the end of the 40s, the first state policy in the field of adult education was implemented. Literacy campaigns were conducted throughout Brazil. In the early 1960s, educational and popular cultural movements associated with community organizations, the Catholic Church, and government agencies developed experiments to teach adults to read and write.

In the United States, the situation is completely different, society looks at the problem in question differently, and one can highlight the features of this view. In 2017, Amy Kraton at the age of 94 became one of the famous older women who graduated from college. She first went to university to earn a Bachelor of Arts degree 
in 1962, but she had to drop it to raise four children. More than 50 years later, a 94year-old student finally got a degree in creative writing and English thanks to the University of South New Hampshire's online program.

However, if you look closely at scholarships and grants, we can see some age restrictions. For example, the Fulbright Fellowship is a 2-year master's degree program funded by the US Department of State. The program also provides grants to graduate students to conduct research activities at the university. The age limit is strictly under 30. Unanimously with some universities in the USA, the Government of the Republic of Korea offers grants for study at its own universities, however, students who enter the bachelor's program should be no older than 25 years old, and students who enter the master's program or graduate school should not be older than 40 years old.

However, not everything is so bad. The American Association of Women's Universities (AAUW) is one of the largest providers of educational programs for women and girls. The AAUW Career Grants Program provides support to women who want to return to work, change their careers, or move up the career ladder after graduating, participating in technical training and continuing education. In recent years, a number of specialized scholarships have been created for older women, often referred to as non-traditional students or students who go to school again, who are interested in gaining professional skills and higher education. Note the following programs:

Alpha Sigma Lambda (ASL)'s Scholarship for Adult Students. The Adult Education Fund offers scholarships to encourage adult students to earn associate and undergraduate degrees. Across the US, ASL has over 300 registered offices. Scholarships are open to adult / non-traditional undergraduate students at accredited colleges or universities that are active leaders in the Alpha Sigma Lambda National Honor Society.

Community Foundation of Sarasota County's Adult Learner Scholarships. The Sarasota County Community Fund provides several scholarships for adult students living along the west coast of Florida. According to the foundation, adult students are students who have not attended high school for a long time and return to complete their higher education by attending a college or vocational school. Community fund scholarships cannot be used in graduate school.

Fast Track Educational Assistance Fund. The foundation was designed to address the emotional, social, educational, and financial needs of non-traditional / 
adult students in Sarasota County. The foundation provides scholarships to adult students who want to pursue a career as a Certified Nurse Assistant (CNA).

Elizabeth Pfiffner Debot Memorial Scholarship. The University Of Wisconsin Point Stevens (UWSP) has established an Elizabeth Piffner Debo Scholarship for non-traditional students. According to UWSP, non-traditional students are students 25 years of age and older who are seeking a bachelor's degree.

P.E.O. Program for Continuing Education (PCE). The mission of the Philanthropic Educational Organization (PEO) is to help women achieve their goals by providing scholarships, loans, awards, grants, and leadership to Cotti College. PEO's Continuing Education Program was created to support women who want to support their family and / or themselves by returning to school to continue their studies that were interrupted.

Society for Women Engineers (SWE) Re-entry / Non-Traditional Scholarships. Refundable / non-traditional scholarships sponsored by the Society of Women Engineers (SWE) help women graduate, so they can re-enter the labor market as engineers. SWE offers a BK scholarship. The foundation was designed to address the emotional, social, educational, and financial needs of non-traditional / adult students in Sarasota County. The foundation provides scholarships to adult students who want to pursue a career as a Certified Nurse Assistant (CNA).Elizabeth Pfiffner Debot Memorial Scholarship. The University Of Wisconsin Point Stevens (UWSP) has established an Elizabeth Piffner Debo Scholarship for non-traditional students. According to UWSP, non-traditional students are students 25 years of age and older who are seeking a bachelor's degree.

P.E.O. Program for Continuing Education (PCE). The mission of the Philanthropic Educational Organization (PEO) is to help women achieve their goals by providing scholarships, loans, awards, grants, and leadership to Cotti College. PEO's Continuing Education Program was created to support women who want to support their family and / or themselves by returning to school to continue their studies that were interrupted.

Society for Women Engineers (SWE) Re-entry / Non-Traditional Scholarships. Refundable / non-traditional scholarships sponsored by the Society of Women Engineers (SWE) help women graduate, so they can re-enter the labor market as engineers. SWE offers the BK Krenzer Memorial Re-entry Scholarship, the Wanda Munn Scholarship, and the Olive Lynn Salembier Reentry Reentry Scholarship for non-traditional students. 
Soroptimist's Women's Opportunity Awards Program. Soroptimist is an international organization for professional and businesspersons working for the benefit of other women and girls. The Women Opportunity Awards program is an educational project for women created by the Soroptimist, whose goal is to support women who want to get higher education and professional training to improve their economic situation.

The AAUW Sarasota Branch Elizabeth Parker Scholarship Fund. Established in 2006 by the Sarasot branch of the American University Women's Association (AAUW), the Elizabeth Parker Scholarship Fund provides scholarships to women who want to complete their education by attending a four-year accredited college or university.

The ABWA Sunrise Chapter Scholarship Fund. The American Business Women's Association (ABWA) Sunrise Chapter Scholarship Fund was created to support people in need who are admitted to an accredited university or college. Preference is given to women residents of Sarasota and Manati counties in need of financial assistance. Candidates must have a GPA of 3.0 and a four-year education with a career goal.

The Yourself Scholarship Fund. The Yourself Scholarship Fund was established in 2002 to support adult students in Sarasota County, men or women who are interested in implementing CAN, RN, or LPN patient care programs. To be eligible for scholarships, applicants must be enrolled in a nursing program at the Sarasota County Technical Institute or Manatee Community College. To renew the scholarship, the student must have an average score of 2.8. The main selection criterion is financial need.

The Davis Educational Fund. The Davis Education Fund was created to provide scholarships for adult students, residents of Sarasota County who are interested in a career in medicine or nursing care. Applicants may be men or women enrolled in a vocational education or college under a health program. Scholarship recipients are based on the financial needs of the applicant and his / her educational goals and objectives on the path to a career in healthcare. The above foundations and educational grants are only a small part of the educational opportunities offered to us by the category of women older than 45 years. Note that the activities of AAUW show the effectiveness of the social behavior of the state in relation to its citizens. After all, women who did not receive an education for any of their own reasons in their youth can do this in a fairly mature way, especially, it is important that getting an education can be both higher and secondary professional (paramedic, assistant 
nurse, assistant teacher). The conditions for receiving grants are fairly open and transparent - you need an age older than 25 years (a low age limit is not specified, which suggests that a woman older than 45 years can apply for a grant), proof of her goals and ambitions and financial need.

It should be noted that in the USA such programs are developed at a very high level, private initiative is especially important. Over the years, Experience Works has been helping low-income people, mostly the elderly, find work. Most of his money comes from private foundations such as the Walmart Foundation. Last year, the fund allocated grants of $\$ 6.5$ million to migrant assistance programs. Over the years, the Lilly Endowment Foundation has provided hundreds of millions of dollars to help people learn and find work. In 2009, the fund allocated \$2.3 million to the Indiana Private Enterprise Council to continue the employment program until 2011. The fund also allocated \$2.75 million to Indiana University. To facilitate internships, job placement, and business promotion.

Thus, we can conclude that in the USA in recent years a number of specialized scholarships have been created for older women, who are often called non-traditional students or students who go to school again, who are interested in obtaining professional skills and higher education.

An interesting large-scale study of the situation in the field of educational opportunities for older people, conducted based on 42 countries (Findsen \& Formosa, 2016). The following aspects of adult education of the third and fourth age were considered on a global scale:

- What historical features have influenced the development of adult and older education?

- What organizations and people have contributed to the formation and development of adult and older education?

- What is the education of adults and older people today (its main characteristics, structure and organization, as well as relevant legislation)?

- What are the key concepts and / or theoretical perspectives that determined the implementation of adult and older education?

- How did the state promote / impede the development of opportunities for adults and older people?

- Which groups of society receive the greatest benefit from the existing system, and which - the least?

- What are the key challenges teachers face in supporting adult and older education? 
- What does the future look like for adults and seniors?

- What are the successful initiatives for educating adults and seniors?

A number of conclusions were made. The features of the historical and cultural development of various countries have greatly influenced the situation in the field of adult education. For example, in China, where Confucianism is widespread, in Malaysia and Indonesia, where religious views, in particular, those related to Islam, have led to the emergence of institutions for adult education. So, one of them is mosques. The government can actively support their activities. In secular states (USA, Australia), the church may provide an opportunity for adult education, but this is not necessarily supported by the government. The situation is radically different in different countries. In the United States, for example, there is long-standing support for adult educational initiatives at the federal and state levels; which contrasts sharply with the situation in Colombia, where the dominant pattern of neglect of older people is considered the norm. Indeed, the relatively high degree of social exclusion of older people on the South American continent has led to the emergence of an older education movement led by nongovernmental organizations that have promoted ideas to improve the quality of life of older people through empowerment programs.

The concept of productive aging is of great importance all over the world due to the merger of three major trends: demographic, economic and sociocultural. The demographic trend is that more people live longer, healthier. Currently, many people, even in their 70s, 80s, and 90s, are ready to participate in society and make a useful contribution. The economic trend is that information age technologies are changing perceptions of productivity. Indeed, the most cost-effective work currently involves the use of human capital, rather than mechanisms. This transition has many consequences, and one of them is that middle-aged and older people can participate in the economy of the information age as easily as young people can. The sociocultural tendency is that older people may be less likely to retire in subsequent years.

The general human experience of aging has changed dramatically over the past century, especially in the developed regions of the world. People build relationships, contribute to their families and communities, develop skills and gain experience over a life course that can last almost twice as long as people born just 100 years ago can. When "old age" sets in, people are confronted with opportunities, choices and expectations that are significantly different from those that they faced in their youth and middle age, and are largely dependent on the opinion about the effect of aging on abilities and desires. The participation of older people in roles and behaviors that are 
traditionally considered productive is often reduced. As a rule, there is a decrease in participation in the professional sphere. More importantly, people of a certain age often face significant barriers and barriers to continuing to participate in formal productive roles. Although they may desire or even need to participate in these roles, they cannot do this or do it with great difficulty. The society is not sufficiently prepared to provide opportunities for long-term productive interactions with older people (Hinterlong et al., 2001). The growing role of higher education institutions in lifelong learning seems to be a trend in global society. In the context of globalization, higher education has become a recognized significant catalyst for social and economic progress due to the creation, dissemination and application of all forms of knowledge. Although older people in most European countries are underrepresented in formal institutional learning, the historical emergence of adult and older education in Europe is not easy to describe. For example, while in Austria you can trace the early development of vocational education, in other countries such as France and Malta, adult and older education has become a specific industry in traditional universities. In other countries, such as Germany and the Nordic countries, interest has been largely aroused by third sector organizations interested in improving the employment opportunities of older workers, while in southern European countries such as Italy, Portugal, Spain, Greece and Cyprus, initiatives came only after realizing the wastefulness of retirement. An interesting point here is that, although in most countries there have been improvements in the development of education for older people, the opposite is also observed. For example, many undertakings in the Netherlands in the 1980s. Currently completely lost. Although there is now a more positive outlook on aging, innovations have not led to a more active public policy in adult education.

In many countries, there are diverse organizations that provide adult education opportunities. This is most characteristic of rich countries. In developing countries, non-governmental organizations are the most active. They can interact with the government. The role of universities in educating older people is a complex issue. One extreme is the case of Colombia, where older people have low social status and are completely ignored by universities, reflecting a wider social ailment. In more developed countries (for example, Germany, the USA, Canada), universities are crucial for providing adult education, however, services are offered primarily for wealthy individuals. In some African countries, adult and continuing education have played an important role in community development. In some countries, there are examples of individuals who have fundamentally affected the state of education for 
older people. Therefore, in the UK, Frank Glendenning improved the visibility of educational gerontology, turning it into a serious area of research. The influence of at least two people stands out: Julius Nyerere in Tanzania, who advocated a special approach to adult education, in which cooperation and empowerment became decisive for the development of statehood; Grundtwig in Denmark (and neighboring northern countries), where enlightenment, creativity, and humanism were hallmarks of adult education in the Scandinavian system.

In general, we can highlight that the problem of changing social behavior in terms of changing social attitudes and stereotypes regarding labor ageism can be implemented with the support of the state. People over 45 can get a second chance to start a new career, having received the opportunity of free education, student grants and the support of entrepreneurs over 45 years old. The transformation of such social positions, in our opinion, will compensate for the shortage of labor resources, improve the quality of life of people over 45 , economic effects in the form of an increase in tax resources and economic development, and increase the social responsibility of employers. Using the example of the problem of labor and educational discrimination of people over 45 years old as an example, we can observe the significance of social behavior for the development and evolution of society as a whole.

It is believed that retraining unemployed professionals over 45 years old is an effective and necessary tool to combat age-related unemployment. In many countries of the world, there are state retraining programs and retraining programs for the third sector. However, there are very few systematic studies of the effectiveness of these programs, nor are violations of age discrimination studied. Among people over 45, there are high-level professionals, unskilled workers, and workers who are considered quite qualified, but whose area of competence is rather vague, such as office personnel. It is clear that they will all study, if they do, in different ways and in different ways.

What exactly is taught to the unemployed over 45? Moreover, what should they learn? The basics of professions new to them, one or another specific skill, for example, computer literacy or something completely different, say, the ability to communicate? It is likely that it is difficult to answer this question in the framework of this article, but these three different lines of training can be noted: training in professions, training in actual concrete skills, and personal development trainings. 
However, it should be borne in mind that in developed European countries there are crises when there are very few vacancies for highly qualified specialists. There are several main trends in teaching people over 45 :

- training in creating new jobs, including in a pinch - only for oneself, developing skills of a small entrepreneur or freelancer, teaching distant work;

- Training in the creation of clubs and micro social public associations that perform the functions of mutual psychological, social and economic support;

- The creation of state and public services of social and psychological support and counseling for people in crises;

- Detailed information on social rights, on all possible benefits and social benefits that a person can receive in a crisis, legal education.

We note the possible social consequences of improper training, or the refusal of scholarship support and grants for people over 45 years of age:

- An attempt to fill vacancies of low-paid unskilled labor by unemployed agerelated specialists is counterproductive in every sense. It is only natural that such attempts meet resistance from the diplomats of the "third age".

- An attempt to retrain, for example, an accountant as a cloakroom attendant or a process engineer as a cleaning machine operator, can be considered as retraining only by misunderstanding or maliciously, since in such cases there can be no talk of any professional retraining.- If, for some reason, people are forced to make such a change in their lives, they need supportive counseling and, possibly, some psychotherapy, and not the highly professional retraining programs themselves.

Economic and social discrimination (Abuladze \& Perek-Białas, 2018) results from attitudes towards the education and retraining of people aged 45. Grants for the training and opening of business enterprises are provided with a limit of up to 35 years. At the same time, many research centers sound the alarm that there are fewer young able-bodied citizens, and therefore there will be no one to receive these grants, since young people basically have difficulties mainly with work experience, try to get a professional status and develop him through work experience. Whereas people over 45 years of age who have experience in a particular field, have difficulty finding a new job, the ability to change their qualifications or professions, they face some age discrimination in job offers.

Allocating resources for adult education in most countries is a low priority (Scandinavian countries are an exception). Financing third-generation education in many countries lags behind the realities that citizens face. Therefore, it is not surprising that the education of the elderly gets negligible in terms of financing, if it 
is truly officially recognized and not made invisible. In many countries, such as China, where the gap between urban and rural areas is very large, there are serious differences. However, lifelong education may receive indirect support through other categories of social security. Thus, an intelligent strategy was adopted in some cases to strengthen the ties of older people in other social areas where funding is less controversial (for example, healthcare).

Among the many problems encountered in different countries, there is a sharp inattention or neglect of people at their fourth age. In Malta, for example, people at their fourth age (heavily dependent on others) are deprived of priority by the government, and usually the family should take care of the senior members. In addition, this assistance falls disproportionately to older women, since, as a rule, the proportion of women in late adulthood in any country is higher than among men, and women are more likely to work stereotypically in the household. In Japan and other neighboring countries, where society is aging rapidly (for example, the Republic of Korea), the question of how people at their fourth age receive care and education is extremely relevant. It is worth mentioning here that in Japan there is the problem of suicide, especially at the age of over 80 . It is believed that a contributing factor is related issues of loneliness and social exclusion (Findsen \& Formosa, 2016).

As we move towards the dawn of a new demographic era, the prospect of productive aging highlights another dimension of later life, recognizing the current and potential contributions of older people through meaningful actions. By emphasizing opportunities, proponents of productive aging hope to provide older people with the opportunity to choose the forms of participation that best suit their needs, interests and skills, and which can bring benefit others. Older people are currently facing a number of very limited opportunities, despite notable successes in our ability to maintain and improve functional abilities in old age. Many older people seek less significant participation or roles for which there are no market equivalents, no compensation, little recognition, and little institutional support. Proponents of productive aging argue that society simply cannot afford to continue to overlook the potential of the elderly as a resource for social change and economic growth. Moreover, they argue that older people's rejection of opportunities for productive participation can give greater confidence in the debate on equality between generations. Productive aging first gained confidence among advocates as a response to ageism, and only recently in academia has attracted attention as a useful construct. As a propaganda position, supporting productive aging implies benefits for both the individual and society. There is evidence to support the general assertion that 
productive participation is good for oneself and others, especially in later life (Hinterlong et al., 2001).

As a result and consequence of the support of such social behavior in society, it seems to us not only a decrease in economic effects, but also the loss of socially significant functions by people over 45 years old and the distortion of social attitudes and stereotypes that cause discriminatory practices in relation to people over 45 years of age. There is a tendency to refuse to finance education for people over 45 years old, despite the fact that they have significant experience, extensive knowledge, and high motivation. The absence of a system of grants and scholarships for this category of people in most countries at the present stage demonstrates the presence of ageism, obstacles to successful activities, and the possibility of advanced training for a large category of the population.

In today's world, education is increasingly seen as the key to a good future. However, it is obvious that educational opportunities are far from equal. Even in developed countries such as the United States (despite fairly well functioning credit markets and free compulsory education before college), there are clear differences in educational outcomes, as well as in college and graduation rates across different demographic groups.

The formation and dissemination of knowledge has been and continues to be the central tasks of universities and equivalent higher education institutions. Traditionally, the dissemination task was carried out by transferring knowledge through classroom instruction, mainly through face-to-face courses, to a selected group of young people aged 18 to 25 years. This model is currently undergoing gradual, but radical changes due to a number of strong socio-economic changes. Thus, despite the fact that classroom teaching, full-time courses, and students of a traditional age can still be the dominant model in higher education, providing education outside the institution, self-study, part-time education and the number of adult students are clearly is growing. Although in the past adults were infrequently accepted as students in higher education institutions, today they represent a real "new group" in universities and other higher education institutions, which is becoming increasingly important. Previously, even in those few institutions where there was a tradition of academic support for adults, adult participation was - with the exception of the post-war years, when many former military personnel continued training, which was postponed by the war - was always insignificant, limited to training without a degree through short-term courses by correspondence or external department (Richardson, 1998). Nevertheless, at present, adult participation has gone 
beyond learning without a degree, distance learning, and is moving from the region to the mission center of universities and other higher education institutions. Thus, adults are not just another new minority group, but, both in number and in importance, they will eventually become in many countries the main part of the population with higher education. However, not all adults participating in higher education programs do this in order to obtain a full degree. In fact, the majority of mature students who study at higher educational institutions are enrolled in continuing education programs with the aim of updating, improving their skills, or developing their personality. Thus, adults are enrolled in a variety of short courses (Rautopuro).

Most countries use a decentralized adult education program, which is characterized by the involvement of a wide range of institutions. As the composition of higher education institutions becomes more diverse, ways should be formed to meet the needs of their non-traditional students. Adult students are independent, willing to learn, and motivated internally to participate in problem-oriented learning. Adult students are demanding consumers of educational services; they have enough experience to recognize the value of learning and the value that it has in $\mathrm{x}$ life.

Conclusions: Thus, the education of people over 45 is a modern problem, due to the obsolescence of previously acquired skills and knowledge, and a high need for new ones. Moreover, despite the existence of a theoretical possibility of education by people of the third and fourth ages, in practice this is in most cases complicated by the lack of scholarship programs that support this phenomenon. The lack of financial support significantly limits the access to education by people who have multiple obligations, which indicates the need for state support in solving this problem.

\section{References}

1. Weber M. The concept of sociology and the "meaning" of social action // General sociology. Reader / Comp. A.G. Zdravomyslov, N.I. Lapin; Per. V.G. Kuzminov; Under the total. ed. N.I. Lapina - M .: Higher. Geek., 2006 .- 783 p.

2. Abuladze L., Perek-Białas J. (2018). Measures of ageism in the labor market in international social studies. In: L. Ayalon, C. Tesch-Römer (eds.). Contemporary perspectives on ageism. Springer, pp. 461-491.

3. Amber D., Domingo J. (2016) The discourse on the unemployment of people over 45 years old in times of crisis. a study of Spanish blogs / Journal of Social Research and Policy. - No. 7 (2), pp. 63-78. 
4. Backes-Gellner, U., Schneider M., Veen S. (2011). Effect of workforce age on quantitative and qualitative organizational performance: Conceptual framework and case study evidence. Organization Studies, Vol. 32, No. 8, pp. 1103-1121.

5. Bratt, C., Abrams D., Swift H.J., Vauclair C.M., Marques S. (2018). Perceived age discrimination across age in Europe: From an aging society to a society for all ages. Development Psychology, Vol. 54, No. 1, pp. 167-180.

6. Chou, W. H., Lai, Y. T., \& Liu, K. H. (2010). Decent digital social media for senior life: A practical design approach. Computer Science and Information Technology (ICCSIT), 2010 3rd IEEE International Conference, 4, pp. 249-253. https://doi.org/10.1109/ICCSIT.2010.5565189

7. De la Rosa, J. N. (2014). Del "Que se vayan todos" al "No nos representan". Respuestas a la crisis económica en Argentina y España [From "Let everyone go" to "Do not represent us". Responses to the economic crisis in Argentina and Spain]. Ágora, 1 (2), pp. 101-116. doi: 10.6035 / Kult-ur.2014.1.2.5.

8. Dubar, C. (2002). La crisis de las identidades. La interpretación de una mutación [The identity crisis. The interpretation of a mutation]. Barcelona: Edicions Bellaterra.

9. Eurydice (2015). Adult Education and Training in Europe: Widening Access to Learning Opportunities. Eurydice Report. Luxembourg: Publications Office of the European Union.

10. Findsen, B. \& Formosa, M. (2016) International Perspectives on Older Adult Education Research, Policies and Practice. New York: Springer.

11. Hinterlong, M.S. W., Morrow-Howell, N., Sherraden M. (2001) Productive aging: principles and perspectives. In Productive Aging: Concepts and Challenges. Baltimore, London: The John Hopkins University Press, pp 3-18.

12. Knowles, M.S., Holton, E.F., Swanson, R.A. (2005) The adult learner: The definitive classic in adult education and human resource development (6th ed.). Burlington, MA: Elsevier.

13. Liu, S.F. \& Rees, F. (2001) The Role of Adult Education in Workplace Ageism. In Making Space: Merging theory and practice in adult learning pp. Westport: Bergin \& Garvey, pp. 138-152.

14. Lynch K.A Profile of Mature Students in Higher Education and an Analysis of Equality Issues [Electron. resource]. URL: http://www.ucc.ie/ publications/heeu/Mature/mature_8.htm.

15. Macnicol, J. (2006) Age Discrimination: An Historical and Contemporary Analysis. Cambridge: Cambridge University Press. 
16. Óhidy, A. (2008) Lifelong Learning Interpretations of an Education Policy in Europe. Wiesbaden: VS Verlag für Sozialwissenschaften

17. Osborne M. Increasing or Widening Participation in Higher Education? A European Overview / / European Journal of Education. 2003. No. 38 (1). P. 5-24.

18. Osborne, M., Marks, A. and Turner, E. Becoming a mature student: How adult appplicants weigh the advantages and disadvantages of higher education // Higher Education. 2004. Vol. 48, No. 3. P. 291-315.

19. Rautopuro, J. and Vaisanen, P. Non-traditional students at university: a follow-up study of young and adult students' orientations, satisfaction and learning outcomes. Paper presented at the European Conference on Educational Research, Lille, 5-8 September 2001 [Electron. resource]. URL: http://www.leeds.ac.uk/educol/documents/ 00001880.htm.

20. Raymond, G. (2001) Age Discrimination in the American Workplace: Old at a Young Age. New Brunswick, New Jersey, and London: Rutgers University Press.

21. Richardson, J., King, E. Adult students in higher education: Burden or Boon? // Journal of higher education. Columbus 1998. Vol. 69, No. 1. P. 65-88.

22. Sargeant, M. Ageism and age discrimination (2011) In Age Discrimination and Diversity: Multiple Discrimination from an Age Perspective. Cambridge: Cambridge University Press. pp. 1-15.

23. SEPE (2015). Datos de los registros del servicio público de empleo estatal. Demandantes de Empleo, Paro, Contratos y Prestaciones por Desempleo. Enero 2015 [Data of the records of the state public employment service. Claimants of Employment, Unemployment, Contracts and Unemployment Benefits. January 2015]. Retrieved March 2, 2015, from http://www.sepe.es/contenidos/ que_es_el_sepe/estadisticas/datos_avance/datos/datos_201 5/ AV_SISPE_1501.pdf

24. Traxler, J. (2013) Mobile Learning Across Developing and Developed Worlds - Tackling Distance, Digital Divides, Disadvantage, Disenfranchisement, In 